American Journal of Applied Sciences 7 (1): 51-55, 2010

ISSN 1546-9239

(C) 2010 Science Publications

\title{
Spatial Variability of Irrigation Water Percolation Rates and Its Relation to Rice Productivity
}

\author{
${ }^{1}$ W. Aimrun, ${ }^{1,2}$ M.S.M. Amin and ${ }^{1}$ A. Gholizadeh \\ ${ }^{1}$ Smart Farming Technology Laboratory, Institute of Advanced Technology, \\ University Putra Malaysia, 43400, Serdang, Selangor, Malaysia \\ ${ }^{2}$ Department of Biology and Agricultural Engineering, Faculty of Engineering, \\ University Putra Malaysia, 43400, Serdang, Selangor, Malaysia
}

\begin{abstract}
Problem statement: Study on spatial variability of vertical saturated hydraulic conductivity or percolation loss was conducted within a plot of an area of 1.2 ha paddy plot to find out the relationship between percolation rate and rice productivity. A paddy soil condition that permits percolation rate of 10-20 mm irrigation water day $^{-1}$ was recommended in order to get high yield of rice. This value is very high when compared to typical values from 1-4 mm day ${ }^{-1}$ for the Malaysian engineers practiced in paddy fields. Approach: This study presented results of a study that relate the distribution of percolation rates with respect to rice yield productivity. Soil samples at 36 sampling points were collected. DGPS was used to locate the sampling points and then rice yields of the same point were collected. The relationship was determined by statistical correlation factor. Kriging method was used to map the distribution of percolation and yield. Results: The results of the study showed that percolation loss was very low and varied even within a small area. Spatial variability maps show that the area of high percolation rates is the same area that produced high yield. Even though high yields can be obtained from the areas of high percolation rate, it may not be the optimum rate. Conclusion: Higher yield within the area of high percolation may be due to less toxic since it is easily be drained out.
\end{abstract}

Key words: Hardpan layer, Kriging, paddy soils, soil water movement

\section{INTRODUCTION}

Understanding the distribution of vertical movement of water or deep percolation loss within an irrigated area is important in precision farming of rice in view of improving efficiency of the irrigation water supply. The information will allow the irrigation engineer or manager to manage the irrigation water more precisely, timely and cost effectively.

The soils of the paddy fields present three distinct layers. The first layer (topsoil) up to $10 \mathrm{~cm}$ from the surface presents many coarse roots and the soil is black. The second layer (hardpan), usually between 10 and $30 \mathrm{~cm}$ from the surface, presents few tiny roots, black or dark brown with yellow mottles and drier than the first layer. The hardpan layer was harder to penetrate and no roots are found in the subsoil layer with grey, brown or dark brown colored soils (Aimrun et al., 2002).

The prevention of excessive percolation of the hardpan layer is necessary for efficient rice production
(Brady, 1980). Kawaguchi and Kyuma (1977) suggest from their experience in Japan that physical conditions which permit percolation of $10-20 \mathrm{~mm}$ irrigation water day $^{-1}$ are necessary for high yields (Kawaguchi and Kyuma, 1977). A puddled or compacted soil (hardpan layer) is generally preferred for paddy rice production (Ghildyal, 1978), both for efficiency of water utilization and for yield. Proper management and control of water is essential to attain the high yields common in Japan and China.

If the high percolation as $10-20 \mathrm{~mm} \mathrm{day}^{-1}$ as in Japan is needed for obtaining high yields, the amount of the water supply must be increased. This will further increase the pressure on our water resources and does not satisfy the irrigation efficiency target. But some research indicated that the high percolation is needed only once in a while, say after 5-10 years of cultivation, to break down or puncture the hardpan layer and let the toxic elements such as Ferrous $\left(\mathrm{Fe}^{2+}\right)$ or Ferric $\left(\mathrm{Fe}^{3+}\right)$ that has been accumulating for a long time to leach out from the root zone.

Corresponding Author: W. Aimrun, Smart Farming Technology Laboratory, Institute of Advanced Technology, University Putra Malaysia, 43400, Serdang, Selangor, Malaysia 
The purpose of this study was to determine the spatial distribution of percolation loss in relation to rice yield within a paddy plot for use in precision farming of rice where the application of water for rice production will be optimized and hence, increase Water Productivity Index (WPI).

\section{MATERIALS AND METHODS}

This study was conducted at the lot number 2162 of the Sawah Sempadan Rice Irrigation Compartment in Tanjung Karang Rice Irrigation Project. The site is located on a flat coastal plain in the Northwest Selangor Agricultural Development Project (Projek Barat Laut Selangor, PBLS), Malaysia. It is in the district of Kuala Selangor and Sabak Bernam at latitude $3^{\circ} 35^{\prime \prime N}$ and longitude $101^{\circ} 05^{\prime \prime} \mathrm{E}$ which covers an area of about 20,000 ha extending over the length of $40 \mathrm{~km}$ along the coast with a width of $5 \mathrm{~km}$ on average. The main irrigation and drainage canals run parallel with the coast. The soil of the study plot covers by Jawa series (Sulfic Tropaquept). The plot size is approximately 1.2 ha or $60 \times 200 \mathrm{~m}$ and it was divided by a drain to two equal areas namely, A and B. A total of 36 points were collected from A and B as shown in Fig. 1. The sampling point was located by Differential Global Positioning System (DGPS). The samples were taken from three soil layers namely, topsoil, hardpan and subsoil.

Undisturbed soil samples were taken by using ring size of $100 \times 130 \mathrm{~mm}$. The rings were brought to the laboratory in order to measure the $\mathrm{K}_{\mathrm{s}}$ using falling head method (Klute and Dirksen, 1986). Figure 2 shows the schematic of the falling head apparatus which was used in this study. Using this method, $\mathrm{K}_{\mathrm{s}}$ were obtained by the following equation:

$$
\mathrm{K}_{\mathrm{s}}=\frac{\mathrm{aL}}{\mathrm{At}} \ln \left[\frac{\mathrm{H}_{1}}{\mathrm{H}_{2}}\right]
$$

or

$$
\mathrm{K}_{\mathrm{s}}=\left(\frac{\mathrm{d}}{\mathrm{D}}\right)^{2} \frac{\mathrm{L}}{\mathrm{t}} \ln \left[\frac{\mathrm{H}_{1}}{\mathrm{H}_{2}}\right]
$$

Where:

$\mathrm{K}_{\mathrm{s}}=$ Saturated hydraulic conductivity $\left(\mathrm{cm} \mathrm{sec}^{-1}\right)$

$\mathrm{a}=$ Cross sectional area of the standpipe $\left(\mathrm{cm}^{2}\right)$

$\mathrm{A}=$ Cross sectional area of the core or brass ring $\left(\mathrm{cm}^{2}\right)$

$\mathrm{L}=$ The length of the sample in the brass ring $(\mathrm{cm})$

$\mathrm{t}=$ The time required for the water level in the standpipe to fall from $\mathrm{H}_{1}$ to $\mathrm{H}_{2}$ (s)

$\mathrm{H}=$ The height of water in the standpipe relative to the datum $(\mathrm{cm})$

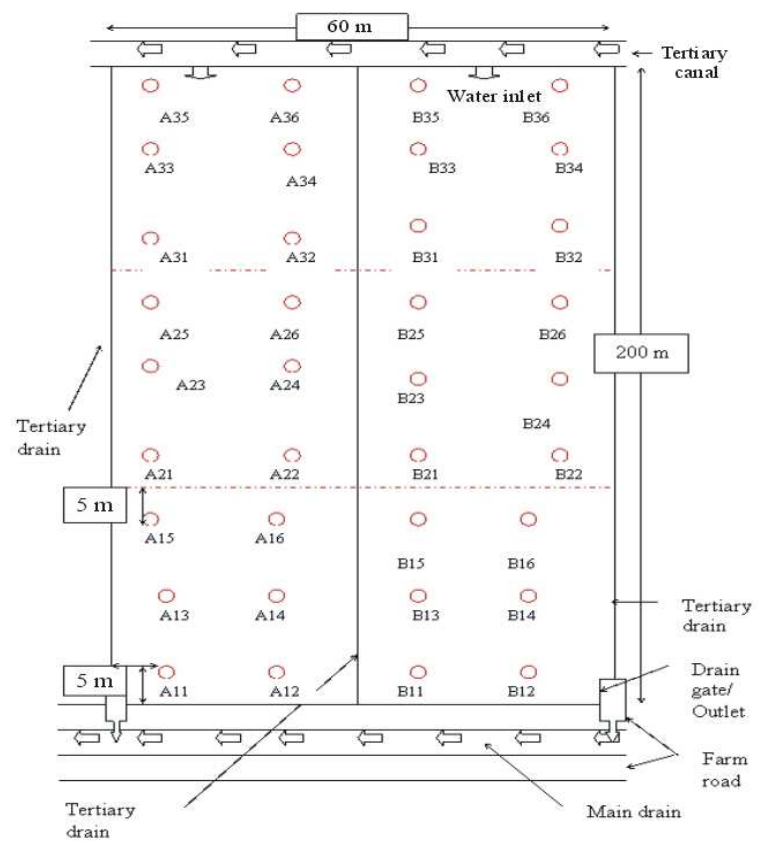

Fig. 1: Sampling points in plot No. 2162 at Sawah Sempadan irrigation compartment

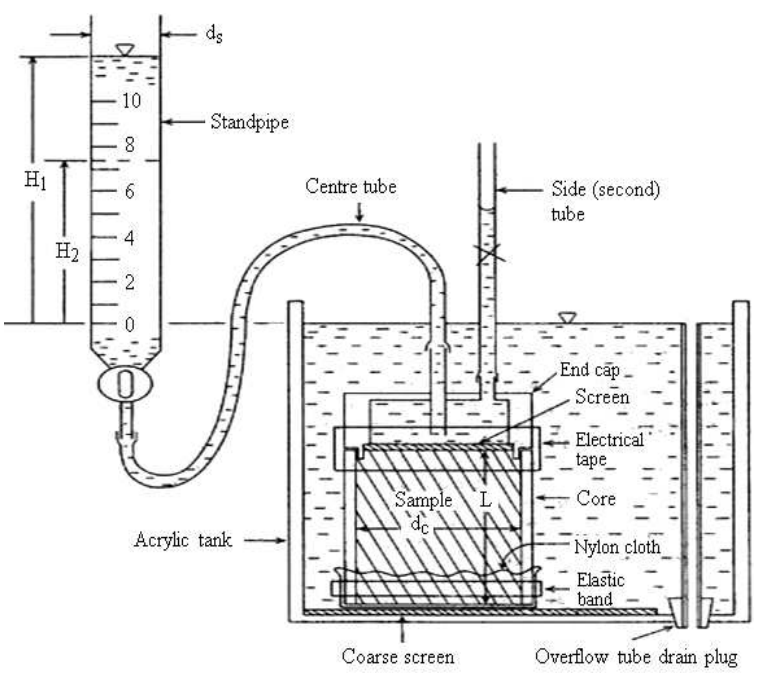

Fig. 2: The falling head permeability apparatus (Carter, 1993)

$\mathrm{d}=$ The internal diameter of the standpipe $(\mathrm{mm})$

$\mathrm{D}=$ The internal diameter of the brass ring $(\mathrm{mm})$

The saturated hydraulic conductivity values were then converted to mm day ${ }^{-1}$. The vertical movement of water was calculated up to $40 \mathrm{~cm}$ depth, i.e., beyond the rice root zone. Vertical movement of saturated 
hydraulic conductivity $\left(\mathrm{K}_{\mathrm{sv}}\right)$ or percolation loss at each particular point was then, calculated using this equation:

$\mathrm{K}_{\mathrm{sv}}=\left[\frac{\sum_{\mathrm{n}=1}^{\mathrm{n}} \mathrm{L}}{\frac{\mathrm{L}_{1}}{\mathrm{~K}_{\mathrm{s} 1}}+\frac{\mathrm{L}_{2}}{\mathrm{~K}_{\mathrm{s} 2}}+\frac{\mathrm{L}_{3}}{\mathrm{~K}_{\mathrm{s} 3}}+\ldots \cdot \frac{\mathrm{L}_{\mathrm{n}}}{\mathrm{K}_{\mathrm{sn}}}}\right]$

Where:

$\mathrm{K}_{\mathrm{sv}}=$ Vertical saturated hydraulic conductivity or percolation $\left(\mathrm{mm} \mathrm{day}^{-1}\right)$

$\mathrm{L}=$ Thickness of the soil layer $(\mathrm{cm})$

$\mathrm{L}_{1} \ldots \mathrm{L}_{\mathrm{n}}=$ The thickness of the soil layer 1 and layer $\mathrm{n}$

$\mathrm{K}_{\mathrm{s} 1} \ldots \mathrm{K}_{\mathrm{sn}}=$ The saturated hydraulic conductivity value of the layer 1 and layer $n$

At the harvesting period, yield data were collected in one square meter area at the soil sampling point. Yield data in gram per meter square were then converted to tonne $\mathrm{ha}^{-1}$.

In order to find out the relationship between percolation and rice yield productivity, percolation values were plotted against yield data by classical statistics. To obtain Kriging map, GS+ Gamma Design Software (Geostatistics for the Environmental Sciences) was used for presenting visualization of percolation and yield productivity distribution within the study plot.

\section{RESULTS}

The result of this study shows that the values of the vertical movement of saturated hydraulic conductivity or percolation loss in the plot were very low. The percolation ranged from 4.31-5.03 mm day ${ }^{-1}$ with the mean and variance of 4.72 and 0.05 , respectively as shown in Table 1.

Yield data was derived based on one square meter basis and then converted to tonnes $\mathrm{ha}^{-1}$. The minimum value was 3.28 tonnes $\mathrm{ha}^{-1}$ and the maximum values was 5.32 tonne ha ${ }^{-1}$ with the mean of 4.48 tonne $\mathrm{ha}^{-1}$ and the variance was 0.27 .

Figure 3 shows the correlation of percolation and yield. The correlation factor was significant at 2 levels $\left(\mathrm{R}^{2}=0.43 * *\right.$ significant at 0.01 level of probability).

Geostatistical analysis and spatial variability map: Kriging analysis was performed in order to estimate the unknown value and zoning the area of the same property and to study the distribution of spatial variability in our study area.
Table 1: Values of percolation and yield from the study plot

\begin{tabular}{lllll}
\hline Parameter & Minimum & Maximum & Mean & Variance \\
\hline Percolation $\left(\mathrm{mm} \mathrm{day}^{-1}\right)$ & 4.31 & 5.03 & 4.72 & 0.05 \\
Yield $\left(\right.$ ton $\left.\mathrm{ha}^{-1}\right)$ & 3.28 & 5.32 & 4.48 & 0.27 \\
\hline
\end{tabular}

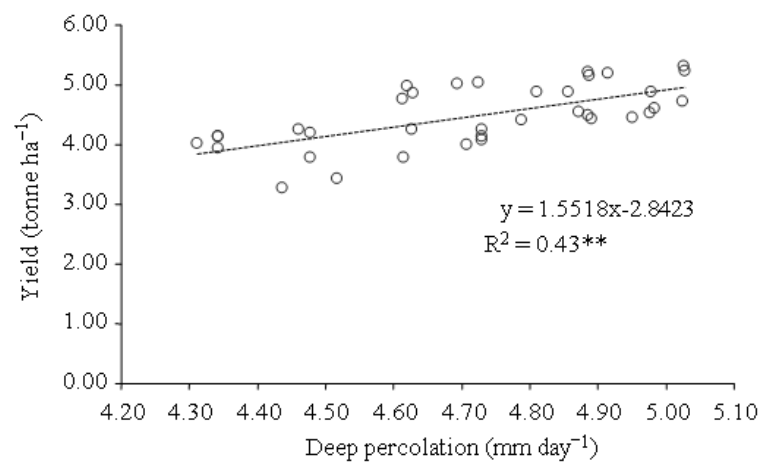

Fig. 3: Relationship between percolation and yield productivity

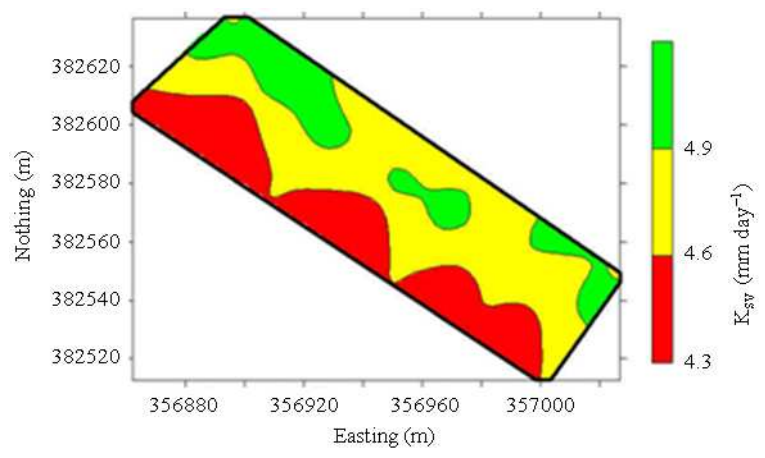

Fig. 4: Spatial variability of percolation loss

Figure 4 shows the spatial variability of percolation loss within the study plot where it was classified into 3 difference levels. The spatial variability of rice yield was classified into 4 difference levels according to Department of Agriculture Malaysia DOA (1997), as shown in Fig. 5 (DOA, 1997). The yield distribution varied across the field, with higher yield at the top right corner.

The spatial variability map of percolation rate is shown in Fig. 4. The high percolation rate was found at the top right side of the field and scattered in the middle and bottom part of the field. The average value of percolation covered the middle part, extending from top to bottom and the lowest value was found at the left side extending from top to bottom of the field. The correlation was found to be significant with yield and percolation. The highest yield was found at the top right corner where the high level of percolation was found. Generally, there was correlation with respect to location as seen from the maps of yield and percolation. 
Am. J. Applied Sci., 7 (1): 51-55, 2010

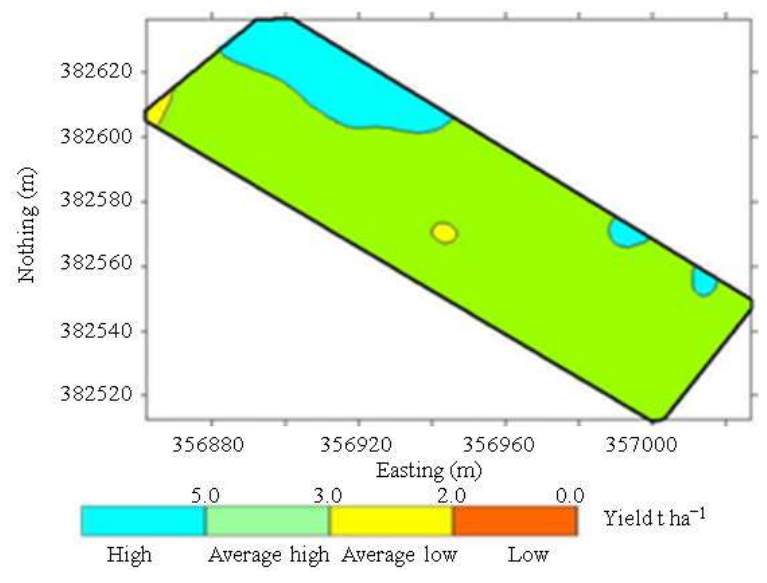

Fig. 5: Spatial variability of rice yield

\section{DISCUSSION}

In rice, reported rates for deep percolation by Tsubo et al. (2005), range from 1-5 mm day ${ }^{-1}$ in heavy clay soils to $25-30 \mathrm{~mm} \mathrm{day}^{-1}$ in sandy and sandy loam soils which is close to this study's result (Tsubo et al., 2005).

In tropical areas, Organic Matter-rich soils may accumulate toxins in the root zone and in the absence of proper leaching, may experience lower rice grain yield (Govindasamy and Chandrasekaran, 1979). Sasaki (2006) reported that iron and manganese concentrations in the subsoil layer were higher in the portion with closed system percolation than those in the portion with open system percolation (Sasaki, 2006). An increase of the percolation rate theoretically results in slightly more oxidized conditions, as more oxygen-rich water is transported through the topsoil and at the same time results in increased leaching of toxic elements and supplies oxygen to the rhizosphere and enhances root activity (Hanhart et al., 1997; Bhagat et al., 1999). Thus, for these situations, some percolation to flush down toxins from the root zone may help increase rice yield (Sharma et al., 1989). The high percolation is needed only once in a while, say after 5-10 years of cultivation, to break down or puncture the hardpan layer and let the toxic elements such as Ferrous $\left(\mathrm{Fe}^{2+}\right)$ or Ferric $\left(\mathrm{Fe}^{3+}\right)$ that has been accumulating for a long time to leach out from the root zone, especially for acid sulfate soil like in this study area. One of the techniques to increase percolation rate and finally remove toxin is the use of moldboard plow (Malone et al., 2003).

\section{CONCLUSION}

- Percolation loss was found to be varied even within a small area such as in the 1.2 ha study area
- There was a positive correlation between percolation rate and rice yield where the areas with high percolation also produced the high rice yield. This result suggests that there is a need to provide a high percolation rate to let the toxic chemicals to leach out from the root zone, probably to break or puncture the hardpan layer once in a few years of cultivation

- Knowing the spatial losses of water beyond the root zone is important for precise management of the irrigation water. The information can be used to supply the irrigation water at difference rates to paddy fields within an irrigation compartment

\section{ACKNOWLEDGEMENT}

The researchers would like to thank the financial support from UPM-MACRES Precision Farming Research Grant. The assistance from all staff at the Smart Farming Technology Lab, ITMA, UPM is gratefully acknowledged.

\section{REFERENCES}

Aimrun, W., M.S.M. Amin, M.M. Mokhtaruddin and S.M. Eltaib, 2002. Determination of soil physical properties in lowland rice area of Tanjung Karang irrigation scheme Malaysia. Proceeding of the 2nd World Engineering Congress, July 2002, Kuching, Sarawak, Malaysia, pp: 363-368.

Bhagat, R.M., S.I. Bhuiyan and K. Moody, 1999. Water, tillage and weed management options for wet seeded rice in the Philippines. Soil Tillage Res., 52: 51-58. DOI: 10.1016/S01671987(99)00057-4

Brady, N.C., 1980. Soil factors that influence rice production. Proceedings of the Symposium on Paddy Soils, (PS'80), Institute of Soil Science, Academia Sinica, Science Press, Biejing, pp: 1-19.

Carter, R.M., 1993. Soil Sampling and Methods of Analysis. Canadian Society of Soil Science, Lewis, Florida, pp: 823.

DOA., 1997. Rating for Chemical Properties of Soil in Peninsular Malaysia. Soil Management Division, Department of Agricultural (DOA), Malaysia.

Ghildyal, B.P., 1978. Effect of Compaction and Puddling on Soil Physical Properties and Rice Growth. International Rice Research Institute, Soils Rice, Los Banos, pp: 317-336.

Govindasamy, R. and S. Chandrasekaran, 1979. Inhibitory effect of rice straw incorporation in illdrained Annamalai clay soil on rice. J. Indian Soc. Soil Sci., 27: 92-94. 
Hanhart, K., V.N. Duong, N. Bakker, F. Bil and I. Postma et al., 1997. Surface water management under varying drainage conditions for rice on an acid sulphate soil in the Mekong delta. Vietnam. Agric. Water Manage., 33: 99-116.

Kawaguchi, K. and K. Kyuma, 1977. Paddy Soils in Tropical Asia: Their Material Nature and Fertility. The University Press of Hawaii, Honolulu, Hawaii.

Klute, A. and C. Dirksen, 1986. Hydraulic Conductivity and Diffusivity: Laboratory Methods. In: Methods of Soil Analysis, Part 1st, Klute, A. (Ed.). American Society Agronomy, ASA and SSSA, Madison, WI., pp: 687-734.

Malone, R.W., S. Logsdon, M.J. Shipitalo, L. Ahuja and J. Weatherington-Rice et al., 2003. Tillage effect on macro porosity and herbicide transport in percolate. Geoderma, 116: 191-215. DOI: 10.1016/S0016-7061(03)00101-0
Sasaki, C., 2006. Experimental study on the influence of percolation patterns on the removal of soluble elements in stratified alluvial-soil paddy fields for rice. Paddy Water Environ., 4: 89-99. DOI: 10.1007/s10333-006-0036-8

Sharma, P.K., S.K. de Datta and C.A. Redulla, 1989. Effect of percolation rate on nutrient kinetics and rice yield in tropical rice soils: I. Role of soil organic matter. Plant Soil, 119: 111-119.

Tsubo, M., S. Fukai, J. Basnayake, T.P. Tuong and B. Bouman et al., 2005. Estimating percolation and lateral water flow on sloping land in rainfed rice ecosystem. Plant Prod. Sci., 8: 354-357. 